\title{
Spinal Arachnoiditis
}

\author{
Stephen I. Esses and T.P. Morley
}

\begin{abstract}
SUMMARY: A review of the literature points to the many causes of arachnoiditis and the failure of treatment to arrest or reverse its effects. The true incidence cannot be determined, although it is probably lower than might at first appear from the published articles. In the radiological literature the diagnosis seems to derive from an examination of the films alone, often without reference to the clinical findings or appearance at operation. While attempts at treatment are usually unsuccessful, some iatrogenic cases can be prevented by the avoidance of intrathecal steroid injections or unduly rough or repeated surgical exploration of the lumbar vertebral canal.
\end{abstract}

RÉSUMÉ: Une revue de la littérature indique clairement que l'arachnoidite peut être due à plusieurs causes et que son traitement est déficitaire. L'incidence réelle de l'arachnoidite ne peut être déterminée, mais elle est probablement inférieure au taux apparent selon les publications. Ainsi dans la littérature radiologique on semble établir un diagnostic sur la base des films sans tenir compte des aspects cliniques ou de la présentation chirurgicale. Quoique les essais thérapeutiques soient généralement négatifs, on peut prévenir certaines causes iatrogéniques en évitant les injections intrathécales de stéroides ou les explorations répétées, ou trop dures, du canal vertébral lombaire.

Can. J. Neurol. Sci. 1983; 10:2-10

Feodor Krause (1907) was the first to describe adhesive lumbar arachnoiditis. By 1936 Elkington presented a complete analysis of forty-one cases under the title "Meningitis Serosa Circumscripta Spinalis". Since that time a variety of clinical features which accompany this condition as well as its numerous causes has been recognized. With the decline of tuberculosis and syphilis, the number of cases due to infection has dwindled, but with the increase of myelography, involving a variety of intrathecal contrast media, arachnoiditis remains a major consideration in the differential diagnosis in low back pain. In spite of the extensive literature dealing with arachnoiditis and its variants, the diagnosis is not readily made. Perhaps this reluctance is due to the poor results of treatment; almost any other diagnosis carries a better prognosis. The purpose of this article is to review the causes, diagnosis, and treatment of spinal arachnoiditis.

\section{ANATOMY AND PATHOPHYSIOLOGY}

Although the arachnoid and subarachnoid space is devoid of vessels, both the pia and dura mater are extremely vascular. Thus the inflammatory response must originate from either the pia or dura. The inflammatory response of the pia following trauma occurs after minimal stimulation. The dura can participate in the production of dural - leptomeningeal adhesions without injury (Lear and Harvey, 1924).

Burton (1978) described three stages of the inflammatory response of the pia-arachnoid. (a) Initially, there is hyperemia and swelling of the nerve roots. This radiculitis is characterized by minimal fibroblast proliferation. (b) The next stage is arachnoiditis with progressive fibroblast proliferation and collagen deposition between nerve roots and pia-arachnoid. Although the swelling subsides, the roots are adherent to each other and to the pia-arachnoid. (c) Adhesive arachnoiditis is the end stage of the inflammatory process marked by pia-arachnoid proliferation with dense collagen deposition which completely encases the nerve roots. The roots are deprived of their blood supply and undergo progressive atrophy. The process may involve the root sleeves alone, or it may involve the subarachnoid space as well. The inflammatory changes can occasionally give rise to isolated cystic collections of cerebrospinal fluid (Long and Rachmaninoff, 1967).

Quiles et al (1978) reviewed tissue obtained from 10 patients with lumbar adhesive arachnoiditis. The most common lesion was fibrosis and/or hyalinization of the arachnoid. Chronic inflammatory cells were seen in three patients, and deposition of calcium was identified in one. Using the scanning electron microscope, Dujovny et al (1978) have identified two basic surface patterns of the normal canine arachnoid membrane: one fenestrated and the other embossed with parallel fibers. By promoting arachnoiditis with radiological contrast agents they noted, under the scanning electron microscope, invasion by macrophages and obliteration of the fenestration by a fibrin-like substance.

\section{CAUSES OF AR ACHNOIDITIS}

The major causes of arachnoiditis are listed in Table 1. Most cases today are due to contrast agents introduced into the subarachnoid space for myelography. Thorium dioxide (Thorotrast) is a radioactive substance which produces a series of radioactive degradation products before becoming lead. It was used in the 1930's and early 1940's as a contrast medium for roentgenologic studies. After numerous. examples of malignant lesions had been documented following the use of thorium dioxide it was discarded from clinical practice. Apart from its delayed radiation effects it induced an immediate inflammatory response and there are a number of documented cases of arachnoiditis following its use (Meyer et al, 1978; Dale and Love, 1967; McNeill et al, 1968).

Ethyliodophenylundecylate (Pantopaque) is an iodinized

From the Division of Neurosurgery, Toronto General Hospital and the Department of Surgery, University of Toronto. 
TABLE 1

\section{Causes of Spinal Arachnoiditis}

\section{Agents Introduced Into Subarachnoid Space}

Contrast agents (see Tables II and III)

Blood:

Lombardi et al (1962).

Howland and Curry (1966).

Bergeron et al (1971).

Haughton et al (1978).

Amphotericin B:

Graybill and Ellenbogen (1973).

Methotrexate:

Naiman et al (1970).

Baum and Holton (1972).

Anaesthetic agents: Kennedy et al (1950).

Reisner et al (1980).

Steroid:

Dullerud and Morland (1976).

Nelson (1976).

Abel et al (1977).

Infective

T.B.:

John and Douglas (1975).

Freilich and Swash (1979).

Syphilitic:

Elkington (1936).

Christenson (1942).

Viral:

Brain (1969).

Cryptococcal:

Davidson (1968).

\section{Trauma}

Surgery:

Vertebral injuries:

Feder and Smith (1962).

Benoist et al, (1980).

Lumbar disc lesions:

Teng and Papatheodorou (1967).

Jacobsen and Lester (1969).

Blau and Logue (1961).

Ransford and Harries (1972).

\section{Hereditary}

Duke and Hashimoto (1974).

ester of undecylinic acid. As a contrast agent it has been extensively used for myelography since the mid-1940's. Although its use represents a significant improvement over thorium dioxide, there are disadvantages associated with it. As with all oily contrast media, incomplete mixing with cerebrospinal fluid produces a lack of definition of anatomical detail. When Hurteau et al (1954) reported arachnoiditis following the use of iodized oil contrast, the safety of Pantopaque was questioned. Howland et al (1963) showed experimentally in dogs that arachnoiditis could occur from the use of Pantopaque, particularly in the presence of blood in the cerebrospinal fluid. Later, Howland and Curry (1966) demonstrated that Pantopaque produces mild arachnoiditis when injected by itself into the cisterna magna of dogs. Experimental work using a monkey model (Bergeron et al, 1971) has shown that iophendylate retained in the subarachnoid space is always accompanied by some degree of arachnoidal reaction. There are numerous case reports implicating Pantopaque in the production of arachnoiditis (Erickson, 1979, Greig and Wignall, 1966). Cases have been reported even when the material is removed after the myelographic investigation (Ward et al,
1976). In spite of these reports, the relationship between the use of iophendylate and the development of arachnoiditis remains uncertain. Peterson (1976), reporting his personal experience with thousands of myelograms, stated that he was unaware of a single case of arachnoiditis which could be attributed solely to Pantopaque. On the other hand, Johnson and Burrows (1978) reviewed a series of patients who had had myelography with Pantopaque and who, for various reasons, required myelography again at some later date. Patients submitted to myelography, operation, or any spinal injection before the initial examination, were excluded from the study. The average time interval between myelograms was seven months. In the initial myelograms, $8.0 \mathrm{ml}$. of contrast was used and in only two patients was the medium aspirated at the end of the procedure. Of 54 patients, 40 (74\%) showed by radiological criteria, thecal scarring at the second examination. In patients who had had no operative procedure between the two examinations the incidence was $67 \%$ (Table 2).

Water soluble contrast media were developed to avoid the arachnoiditis associated with oily contrast media and to improve diagnostic precision. Monoiodomethane sulfonate (Kontrast U, Conturex) has been in use in Scandinavia since 1931. Later, meglumine iothalamate (Conray) and meglumine iocarmate (Dimer-X, Dimeray) were introduced. Haughton and colleagues (1977, 1978a, 1978b, 1980) investigated the risk of arachnoiditis from these media using a monkey model. They showed that there is both histologic and radiographic evidence of arachnoiditis produced by these agents. Furthermore, there seems to be some relationship between the concentration of the contrast used and the subsequent development of arachnoiditis. When myelography was performed with meglumine iocarmate in vigorously hydrated monkeys the severity of arachnoiditis was significantly less than in a group of dehydrated animals (Eldevik and Haughton, 1978). Other investigators have confirmed the development of arachnoiditis following the clinical use of these water soluble agents (Dullerud and Morland, 1973; Suolanen, 1977; Johnson and Burrows, 1978; Ahlgren, 1973; Hansen et al, 1978; Liliequist and Lundstrom, 1974; Autio et al, 1972; Irstam and Rosencrantz, 1974 a, 1974 b; Radberg and Wennberg, 1973; Irstam et al, 1974). All these authors have attempted to estimate the incidence of arachnoiditis following the use of these media by reviewing series of patients subjected to a second myelographic examination (Tables 2 and 3 ). Although the incidence varies between authors, meglumine iocarmate, meglumine iothalamate and monoiodomethane sulfonate all cause an appreciable risk of arachnoiditis according to radiographic criteria. Furthermore, most authors reported an increased incidence when spinal surgery was performed between the two radiographic studies (Table 3 ). It should be noted that the diagnosis of arachnoiditis, in the reports cited in Tables 2 and 3 was based on radiographic rather than clinical criteria and most cases lacked confirmation either by inspection at operation or by histological examination.

Metrizamide (Amipaque), developed in the 1970's, is a nonionic monomeric iodinated compound. Although it is water-soluble, the aqueous solution is not stable for longer than 12 hours. It is supplied as a freeze-dried powder and 
TABLE 2

Incidence of Arachnoiditis in Patients Subjected to a Second Myelogram without Intervening Surgery ${ }^{1}$

Authors

Contrast Agent Used At First Myelogram

\begin{tabular}{|c|c|c|c|c|c|}
\hline & $\begin{array}{c}\begin{array}{c}\text { Meglumine } \\
\text { iocarmate } \\
\text { (Dimer-X, Dimeray) }\end{array} \\
\end{array}$ & $\begin{array}{c}\text { Meglumine } \\
\text { iothalamate } \\
\text { (Conray) }\end{array}$ & $\begin{array}{c}\text { Monoiodomethane } \\
\text { sulfonate } \\
\text { (Kontrast U, Conturex) } \\
\end{array}$ & $\begin{array}{c}\text { Ethyliodophenyl- } \\
\text { undecylate } \\
\text { (Pantopaque, Myodil) }\end{array}$ & $\begin{array}{l}\text { Metrizamide } \\
\text { (Amipaque) }\end{array}$ \\
\hline $\begin{array}{l}\text { Dullerud \& Morland } \\
\text { (1973) }\end{array}$ & $0 / 4(0 \%)^{2}$ & & & & \\
\hline $\begin{array}{l}\text { Autio et al } \\
(1972)\end{array}$ & & $6 / 6(100 \%)$ & $0 / 12(0 \%)$ & & \\
\hline $\begin{array}{l}\text { Suolanen } \\
\text { (1977) }\end{array}$ & $6 / 22(27 \%)$ & $13 / 16(81 \%)$ & $13 / 30(43 \%)$ & & \\
\hline $\begin{array}{l}\text { Johnson \& Burrows } \\
\text { (1978) }\end{array}$ & & $10 / 20(50 \%)$ & & $12 / 18(67 \%)$ & \\
\hline $\begin{array}{l}\text { Ahlgren } \\
\text { (1973) }\end{array}$ & $4 / 11(36.5 \%)$ & $8 / 18(44 \%)$ & $11 / 67(16.5 \%)$ & & \\
\hline $\begin{array}{l}\text { Hansen et al } \\
\text { (1978) }\end{array}$ & $1 / 5(20 \%)$ & $5 / 22(23 \%)$ & $1 / 11(9 \%)$ & & $0 / 17(0 \%)$ \\
\hline $\begin{array}{l}\text { Ahlgren } \\
\text { (1978) }\end{array}$ & & & & & $0 / 58(0 \%)$ \\
\hline $\begin{array}{l}\text { Irstam } \\
(1980)\end{array}$ & & & & & $0 / 3(0 \%)$ \\
\hline $\begin{array}{l}\text { Liliequist \& Lundstrom } \\
\text { (1974) }\end{array}$ & & & $7 / 45(16 \%)$ & & \\
\hline $\begin{array}{l}\text { Irstam \& Rosencrantz } \\
\text { (1973) }\end{array}$ & $0 / 7(0 \%)$ & & & & \\
\hline $\begin{array}{l}\text { Radberg \& Wennberg } \\
\text { (1973) }\end{array}$ & & $2 / 3(67 \%)$ & $10 / 21(48 \%)$ & & \\
\hline $\begin{array}{l}\text { Irstam et al } \\
(1974)\end{array}$ & & $1 / 9(11 \%)$ & $8 / 19(42 \%)$ & & \\
\hline Pooled Data & $11 / 49(22 \%)$ & $45 / 94(48 \%)$ & $50 / 205(24 \%)$ & {$[2 / 18(67 \%)$} & $0 / 78(0 \%)$ \\
\hline
\end{tabular}

1. Patients with evidence of arachnoiditis on first myelogram excluded.

2. When contrast was injected with methylprednisolone acetate, incidence of arachnoiditis was $9 / 9$ (100\%).

must be dissolved in water immediately before use. It has low toxicity and does not seem to be associated with arachnoiditis. In monkeys, the incidence of arachnoiditis following metrizamide myelography was no higher than following lumbar puncture and the injection of autologous cerebrospinal fluid (Gaughton and Ho, 1980). Although high concentrations of metrizamide have caused arachnoiditis in monkeys, concentrations comparable to clinical levels appear to be harmless (Haughton et al, 1978 a). Clinical reports confirm its safety with regard to arachnoiditis (Ahlgren, 1978; Hansen et al, 1978; Irstam, 1980) (Table 2), but final judgement will have to await further passage of time. Grainger's (1978) report of 268 patients who had a second water-soluble myelogram after a previous metrizamide myelogram, showed radiologic evidence of adhesive arachnoiditis in only one patient, but lumbar disc surgery had been performed between the two myelograms.

Apart from contrast agents, there are others that, when introduced into the subarachnoid space, provoke inflammation of the pia-arachnoid. Autologous blood injected in- trathecally into monkeys results in mild to moderate arachnoiditis (Haughton et al, 1978 a). Lombardi et al, (1962) described spinal arachnoiditis after subarachnoid haemorrhage. Graybill and Ellenbogen (1973) reported the development of arachnoiditis in five patients with fungal meningitis whose therapy had involved intraventricular amphotericin B delivered through an Ommaya reservoir. Intrathecal methotrexate has also been shown to provoke arachnoiditis even when a diluent containing no preservatives was used (Baum and Hoiton, 1972). In a clinical report by Reisner et al, (1980), adhesive arachnoiditis developed following an inadvertent subarachnoid injection of $3 \% 2$-chloroprocaine.

Although physicians continue to use intrathecal methylprednisolone acetate in the treatment of a variety of conditions, including lumbar radiculopathy, there is good evidence that this can produce arachnoiditis. Eldevik et al (1978) showed in monkeys that $0.15 \mathrm{ml}$. of methylprednisolone intrathecally produced histologic and radiographic evidence of arachnoiditis twelve weeks later. The incidence of arachnoiditis after myelography with meglumine iocar- 
TABLE 3

Incidence of Arachnoiditis in Patients Subjected to a Second Myelogram with Intervening Spinal Surgery

Authors

Contrast Agent Used At First Myelogram

\begin{tabular}{|c|c|c|c|c|c|}
\hline & $\begin{array}{c}\text { Meglumine } \\
\text { iocarmate } \\
\text { (Dimer-X, Dimeray) }\end{array}$ & $\begin{array}{c}\text { Meglumine } \\
\text { iothalamate } \\
\text { (Conray) }\end{array}$ & $\begin{array}{c}\text { Monoiodomethane } \\
\text { sulfonate } \\
\text { (Kontrast U, Conturex) }\end{array}$ & $\begin{array}{c}\text { Ethyliodophenyl- } \\
\text { undecylate } \\
\text { (Pantopaque, Myodil) }\end{array}$ & $\begin{array}{l}\text { Metrizamide } \\
\text { (Amipaque) }\end{array}$ \\
\hline $\begin{array}{l}\text { Dullerud \& Morland } \\
\text { (1973) }\end{array}$ & $2 / 2(100 \%)$ & & & & \\
\hline $\begin{array}{l}\text { Suolanen } \\
\text { (1977) }\end{array}$ & $3 / 10(30 \%)$ & $6 / 7(86 \%)$ & $8 / 14(57 \%)$ & & \\
\hline $\begin{array}{l}\text { Johnson \& Burrows } \\
\text { (1978) }\end{array}$ & & $11 / 16(68 \%)$ & & $27 / 34(79 \%)$ & \\
\hline $\begin{array}{l}\text { Ahlgren } \\
\text { (1973) }\end{array}$ & $25 / 34(73 \%)$ & $31 / 58(53.5 \%)$ & $73 / 173(42 \%)$ & & \\
\hline $\begin{array}{l}\text { Hansen et al } \\
(1978)\end{array}$ & $6 / 7(86 \%)$ & 19/74 (26\%) & $4 / 35(11 \%)$ & & $0 / 73(0 \%)$ \\
\hline $\begin{array}{l}\text { Irstam } \\
(1980)\end{array}$ & & & & & $0 / 10(0 \%)$ \\
\hline $\begin{array}{l}\text { Liliequist \& Lundstrom } \\
\text { (1974) }\end{array}$ & & & $26 / 45(58 \%)$ & & \\
\hline $\begin{array}{l}\text { Irstam \& Rosencrantz } \\
(1974)\end{array}$ & $5 / 12(42 \%)$ & $1 / 3(33 \%)$ & $39 / 50(78 \%)$ & & \\
\hline $\begin{array}{l}\text { Irstam et al } \\
(1974)\end{array}$ & & $1 / 10(10 \%)$ & $6 / 10(60 \%)$ & & \\
\hline Pooled Data & $41 / 65(63 \%)$ & $69 / 168(41 \%)$ & $156 / 327(48 \%)$ & $27 / 34(79 \%)$ & $0 / 83(0 \%)$ \\
\hline
\end{tabular}

nate has been shown to be significantly increased if methylprenisolone is added to the contrast agent (Dullerud and Morland, 1976; Ahlgren, 1973). Goldstein et al (1970) first reported arachnoiditis from administration of methylprednisolone acetate in the treatment of multiple sclerosis. This has also been the experience of Nelson (1976).

Fortunately, arachnoiditis of infectious origin is rare in this country. However, in a review from India of 70 cases of spinal arachnoiditis, 38 were due to tuberculosis (Wadia and Dastur, 1969). Sporadic reports appear in the North American literature of arachnoiditis due to tuberculosis (John and Douglas, 1975) and cryptococcal infection of the central nervous system (Davidson, 1968).

Arachnoiditis may follow accidental spinal trauma such as injury (Teng and Papatheodorou, 1967, Jacobsen and Lester, 1969), but more commonly it is iatrogenic. Benoist et al (1980) reported 38 cases of arachnoiditis in which the etiologic factor common to all patients was lumbar spinal surgery. Clark (1969) suggested that a small lumbar spinal canal increases the risk of arachnoiditis following disc surgery. The repeated trauma to the theca from a prolapsed lumbar disc may provoke arachnoiditis. Ransford and Harries (1972) reported five cases of arachnoiditis due to disc protrusion.

Spinal arachnoiditis may be familial. Duke and Hashimoto $(1973,1974)$ reported six members of a Canadian family of Japanese ancestry who developed chronic adhesive spinal arachnoiditis. Although familial spinal arachnoiditis is rare, some variants are clearly inherited. Iraci et al (1979) reported adhesive arachnoiditis of the opto-chiasmatic cistern in three pairs of brothers. Furthermore, diseases with a genetic basis, such as rheumatoid spondylitis, have also been shown occasionally to result in a syndrome resembling arachnoiditis (Gordon and Yodell, 1973).

\section{DIAGNOSIS}

The diagnosis of spinal arachnoiditis is based on clinical, radiographic and operative findings.

Clinical Presentation. In almost all patients the initial symptom is constant low back and/or leg pain accentuated by activity. Of the series reported by Wilkinson and Schuman (1979), 14 of 17 patients developed neurological symptoms and complained of sensory loss. Usually several roots are involved. Of 80 patients only 5 lacked root signs or had signs limited to only one root (Shaw et al, 1978). In the same series 11 patients became paraparetic and 3 were paraplegic. Bladder disturbance has been reported and may be the presenting symptom (McKenzie, 1971). Neurotrophic arthropathy may complicate progressive adhesive arachnoiditis (Wolfgang, 1972).

Auld (1976, 1978) described a postoperative syndrome that preceded the onset of chronic spinal arachnoiditis. In 25 patients who developed lumbar radiculopathy following spinal surgery, 7 had a strikingly similar postoperative syndrome characterized by transient violent spasms of the legs, muscle cramps, increased radicular pain, fever and chills. The onset of these symptoms usually began on the first or second postoperative day and lasted up to a month. All 7 patients later developed severe lumbar spinal arachnoiditis. 


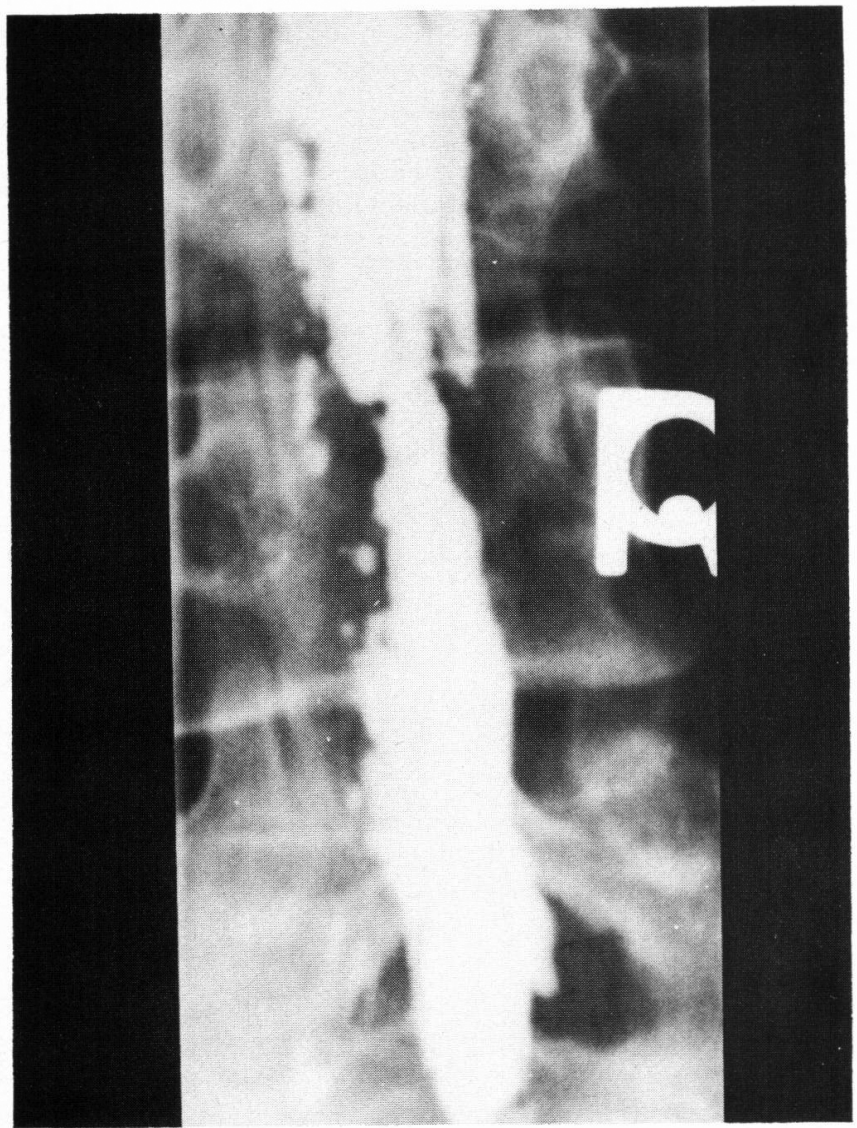

Figure 1 - Oil myelogram of lumbar canal in arachnoiditis.

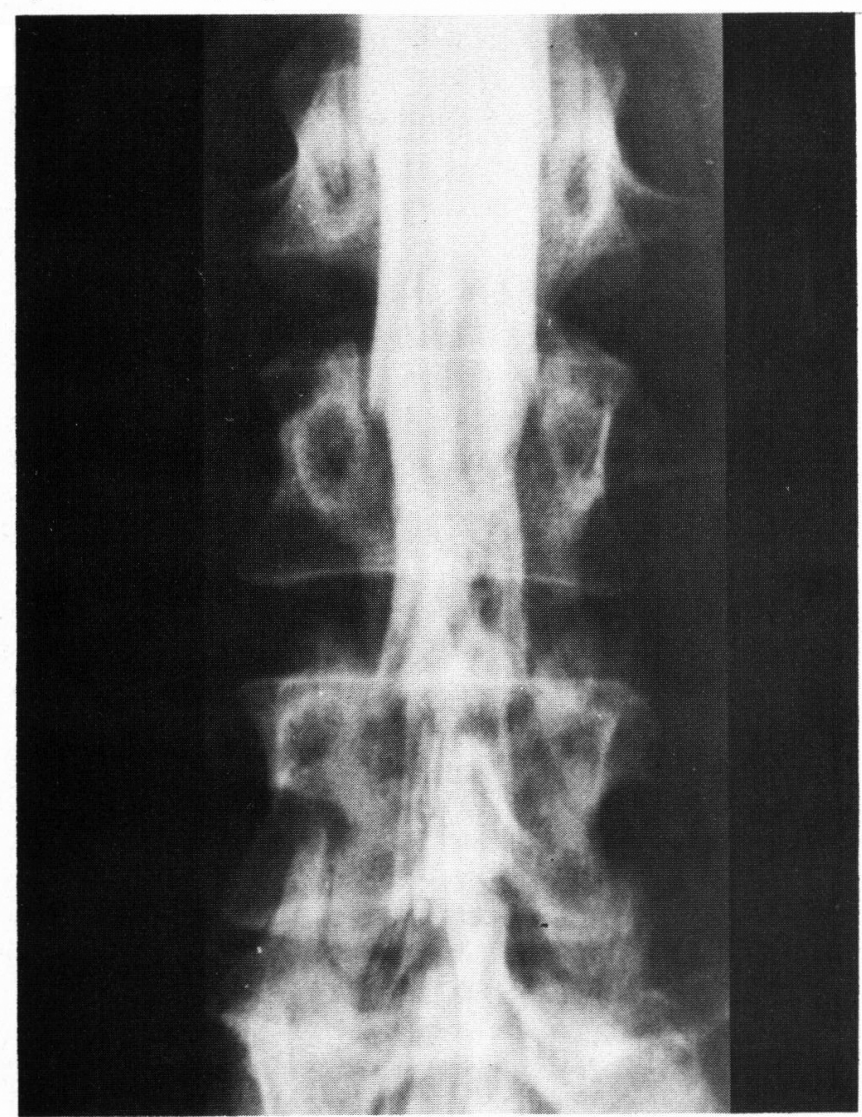

Figure $2-$ Water soluble myelogram of lumbar canal in arachnoiditis.
Arachnoiditis, however, does not inevitably follow this clinical presentation. Benner and Ehni (1978) reviewed 60 cases of spinal arachnoiditis in patients who had had myelography followed by discectomy or laminectomy. Approximately one half developed new symptoms immediately after the operation or the preoperative symptoms became more severe.

The characteristic myelographic pattern of chronic adhesive spinal arachnoiditis is a homogeneous contrast in the lower lumbar sac combined with defective root pocket filling, and narrowing and shortening of the dural sac (Ahlgren, 1973, Irstam and Rosencrantz, 1973, 1974). Jorgensen et al (1975) have divided the radiographic changes into two types. Type $I$ is a pure adhesion of the root to the inside of the meninges in the lower part of the dural sac with a homogenous contrast pattern without root shadows and with a rounded shortening of the root pocket. In type II some proliferation is added inside the dural sac, localized or diffuse, with filling defects, narrowing, shortening, or occlusion of the spinal canal. There is no histologic difference between the two types, and type I was seen to change into type II after repeated trauma (myelography and surgery).

In our experience with cases of surgically verified arachnoiditis, the radiographic appearance is often somewhat different. When an oil medium is used, the column is very irregular in outline and many isolated oil droplets are trapped in the interstices of the adhesions (Figure 1). A water-soluble medium gives a clearer impression of the matting together of the nerve roots (Figure 2). (The two cases illustrated were not surgically verified as arachnoiditis.)

In a review of 80 cases of spinal arachnoiditis, Shaw et al (1978) found that over $80 \%$ had narrowing of the subarachnoid space on the myelogram. Approximately $70 \%$ showed irregular distribution and loculation of the contrast medium. Half of their patients had partial or complete blocks on myelography. Occasionally a normal myelogram is seen in extensive arachnoiditis. This may be due to immobilization of the roots against the dura-which allows the central portion of the subarachnoid space to remain open (Smith, 1972). In 16 cases reported by Auld (1976) in which the diagnosis of arachnoiditis was proved at surgery there were three patients with normal myelograms.

Computerized transverse (CT) axial tomographic scans can be useful in the diagnosis of spinal arachnoiditis (Burton, 1978). CT scanning has already been demonstrated as reliable in basal arachnoiditis (Enzmann et al, 1976).

Other diagnostic procedures are not particularly useful in spinal arachnoiditis. The cerebrospinal fluid protein may be markedly raised in the presence of spinal block due to arachnoiditis (Rao and Dinakar, 1971), but it can also be normal (Shaw et al, 1978). Parker and Kane (1979) attempted to correlate the myelographic and surgical findings with the electromyographic (EMG) changes but failed to find any specific EMG pattern associated with chronic spinal arachnoiditis.

At operation the dura is usually adherent to the arachnoid and the latter is seen to be unmistakably thickened and opaque. There is little difficulty in distinguishing the 


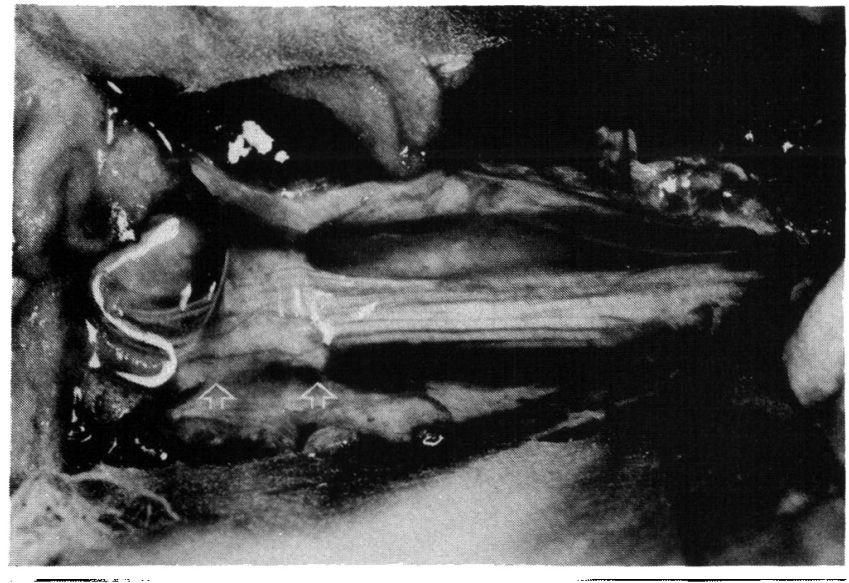

Figure 3 - Focal arachnoiditis in lumbar canal secondary to trauma from herniated disc. The arachnoid has not been opened. The pathological area lies between the arrows.

pathological appearance of true arachnoiditis from the minor variations in thickness and the small plaques of calcium so frequently encountered in the normal spinal arachnoid membrane. The dense fibrosis usually extends throughout the operative field, but in cases secondary to focal injury it may be sharply limited to the site of trauma (Figure 3). Severe neurological deficits occur when fibrosis, obliterating the subarachnoid space, grips the cord and roots in an almost avascular sleeve.

\section{TREATMENT}

\section{Surgical}

The reported results of surgical treatment for patients with spinal arachnoiditis vary; the series are not comparable with regard to length of follow-up or surgical technique.

Decompressive laminectomy is only slightly better than non-surgical treatment (Shaw et al, 1978). Auld (1976) reported initial improvement in half his cases after he had left the dura open at the site of spinal block. However, two years later only $15 \%$ had good relief from pain. Indeed, Compere's experience (1980) has been so unsatisfactory that he doubts any prolonged benefit can be obtained from surgery.

Johnston and Matheny (1978) reported their results from lysis of arachnoid adhesions under the operating microscope. In spite of some short-term improvement, they do not recommend this procedure because symptoms recur, presumably due to reaccumulation of scar tissue. On the other hand, of 17 patients in whom decompressive laminectomy and intradural exploration was performed, Wilkinson and Schuman (1979) found that half enjoyed neurological improvement and relief from pain when reexamined over one year later. In 13 of these cases, operative magnification allowed extensive intradural lysis of roots and dissection of adhesions.

The cause of surgical failure is generally believed to be a reaccumulation of scar tissue. Various means have been attempted to prevent recurrent fibrosis. Colchicine's antifibrotic activity is being investigated by Benoist et al (1980). Lazar and Bland (1979) follow intradural lysis with a Silastic (Dow Chemical Company, Midland) dural patch.
Preliminary results show that cerebrospinal fluid fistula through the operative incision may complicate this technique.

Hoppenstein (1980) recently reported his results of microsurgical dorsal rhizotomy in 26 patients who presented with varying degrees of pain of adhesive arachnoiditis. Seventy-two percent were relieved in the short-term; the benefits of operation appear to be maintained over a longer period of observation. The possibility exists however, of aggravation of the arachnoiditis by intradural rhizotomy (Echols, 1969).

\section{Intrathecal Steroid}

Reports of successful treatment of postoperative arachnoiditis with intrathecal steroids (Savastano, 1968, Tkaczwk, 1976) must be set against the evidence already alluded to of the danger of corticosteroid injected into the subarachnoid space.

\section{Radiotherapy}

Inhibition of adhesion formation by radiotherapy has been recommended (Feder, 1962; Olivia and Parenteau, 1965). In view of the risk of radiation-induced inflammation and fibrosis, however, the advisability of this form of treatment is doubtful.

\section{Pain Relief}

Assuming that the pain of arachnoiditis may be due to deafferentation from extensive perineural fibrosis, Turnbull et al (1980) have used thalamic stimulation. This treatment relieved pain in five of nine patients with lumbar arachnoiditis. Weekly injections of small amounts of local anaesthetic into active acupuncture loci in the low back area have also been used in an attempt to relieve pain due to arachnoiditis. However no improvement was noted in a group of patients treated by this method (Wilber, 1975).

\section{CONCLUSIONS}

The true incidence of spinal arachnoiditis is difficult to determine from the literature since many of the reported cases have been diagnosed solely on the basis of radiologic findings and have not been verified by operation. Often the nature and severity of symptoms and signs are not mentioned and no attempt is made to correlate clinical findings with radiologic appearance.

Since no effective treatment is available, it is important to avoid recognized iatrogenic causes of arachnoiditis such as intrathecal injection of steroids or repeated operative trauma in the treatment of lumbar disc disease.

Surgical exploration may be required to establish the diagnosis, but it is doubtful if it alters the usually progressive natural course of the disease.

\section{Acknowledgement}

The authors thank Dr. R.G. Holgate, Department of Radiology, Toronto General Hospital, for providing radiographs of arachnoiditis. 


\section{REFERENCES}

Abel, R. Jr., Nelson, D.A. and Bernat, J.L. (1977). Complications from methylprednisolone acetate (DepoMedrol) when injected into the orbit, subarachnoid, or subdural spaces. Del. Med. J. 49, 331-343.

Ahlgren, P. (1973). Long term side effects after myelography with water-soluble contrast media: Conturex, Conray Meglumin 282 and Dimer-X. Neuroradiology 6, 206-211.

Ahlgren, P. (1978). Amipaque myelography without late adhesive arachnoid changes. Neuroradiology 14, 231233.

Auld, A.W. (1976). Chronic spinal radiculopathy with particular reference to spinal arachnoiditis. A surgical viewpoint. J. Florida M.A. 63, 889-891.

Auld, A.W. (1978). Chronic spinal arachnoiditis. A postoperative syndrome that may signal its onset. Spine 3, 88-92.

Autio, E., Suolanen, J., Norrback, S. and Slatis, P. (1972). Adhesive arachnoiditis after lumbar myelography with meglumine iothalamate (Conray). Acta Radiol. (Diagn) (Stockh) 12, 17-24.

B aum, E.S. and Holton, C.P. (1972). Intrathecal methotrexate. Lancet 1, 380-381.

Benner, B. and Ehni, G. (1978). Spinal arachnoiditis. The postoperative variety in particular. Spine 3, 40-44.

Benoist, M., Ficat, C., Baraf, P. and Cavehoix, J. (1980). Postoperative lumbar epiduro-arachnoiditis. Spine 5, 432-436.

Bergeron, R.R., Rumbaugh, C.L., Fang, H. and Cravioto, H. (1971). Experimental Pantopaque arachnoiditis in the monkey. Radiology 99, 95-101.

Blau, J. and Logue, V. (1961). Intermittent claudication of the cauda equina. Lancet 1, 1081-1086.

Brain, W.R. (1977). Diseases of the Nervous System. 8th. edition. Oxford, Oxford University Press. 740.

Burton, C.V. (1978). Lumbosacral arachnoiditis. Spine 3, 24-30.

Christensen, E. (1942). Chronic adhesive spinal arachnoiditis. Acta Psychiat. et Neurol. 17, 23-38.

Clark, K. (1969). Significance of the small lumbar spinal canal: cauda equina compression syndromes due to spondylosis. 2. Clinical and surgical significance. J. Neurosurg. 31, 495-498.

Compere, E.L. (1980). Arachnoiditis confusion. Int. Surg. 65, 305-307.

Dale, A.J.D. and Love, J.G. (1967). Thorium dioxide myelopathy. J.A.M.A. 199, 606-609.

Davidson, S. (1968). Cryptococcal spinal arachnoiditis. J. Neurol. Neurosurg. Psychiat. 31, 76-80.

Dujovny, M., Barrionuevo, P.J., Kossovsky, N., Laha, R.K. and Rosenbaum, A.E. (1978). Effects of contrast media on the canine subarachnoid space. Spine 3, 31-35.

Duke, R.J. and Hashimoto, S. (1973). Familial spinal arachnoiditis - a new entity. Trans. Am. Neurol. Assoc. 98, 98-102.

Duke, R.J. and Hashimoto, S.A. (1974). Familial spinal arachnoiditis. A new entity. Arch. Neurol. 30, 300-303.
Dullerud, R. and Morland, T.J. (1976). Adhesive arachnoiditis after lumbar radiculography with Dimer-X and Depo-Medrol. Radiology 119, 153-155.

Echols, D.H. (1969). Sensory rhizotomy following operation for ruptured intervertebral disc. A review of 62 cases. J. Neurosurg. 31, 335-338.

Eldevik, O.P. and Haughton, V.M. (1978). The effect of hydration on the acute and chronic complications of aqueous myelography. Radiology 129, 713-714.

Eldevik, O.P., Haughton, V.M., Ho, K.C., Williams, A.L., Unger, G.F. and Larson, S.J. (1978). Ineffectiveness of prophylactic intrathecal methylprednisolone in myelography with aqueous media. Radiology 129, 99-101.

Elkington, J.St.C. (1936). Meningitis serosa circumscripta spinalis (spinal arachnoiditis). Brain 59, 181-203.

Enzmann, D.R., Norman, D., Mani, J. and Newton, T.H. (1976). Computed tomography of granulomatous basal arachnoiditis. Radiology 120, 341-344.

Erickson, D. (1979). Arachnoiditis caused by Pantopaque (letter). Spine 4, 279-280.

Feder, B.H. and Smith, J.L. (1962). Roentgen therapy in chronic spinal arachnoiditis. Radiology 78, 192-198.

Freilich, D. and Swash, M. (1979). Diagnosis and management of tuberculous paraplegia with special reference and tuberculous radiculomyelitis. J. Neurol. Neurosurg. Psychiatry 42, 12-18.

Goldstein, N.P., McKenzie, B.F., McGuckin, W.F. and Mattox, V.R. (1970). Experimental intrathecal administration and methylprednisolone acetate in multiple sclerosis. Trans. Am. Neurol. Assoc. 95, 243-244.

Gordon, A.L. and Yudell, A. (1973). Cauda equina lesion associated with rheumatoid spondylitis. Ann. Intern. Med. 78, 555-557.

Grainger, R.G. (1978). Chronic spinal arachnoiditis (letter). Br. Med. J. 2, 1294.

Graybill, J.R. and Ellenbogen, C. (1973). Complications with the Ommaya reservoir in patients with granulomatous meningitis. J. Neurosurg. 38, 477-480.

Greig, J.H. and Wignall, N. (1966). A case of arachnoiditis associated with Pantopaque myelography. J. Can. Assoc. Radiol. 17, 198-199.

Hansen, E.B., Fahrenkrug, A. and Praestholm. J. (1978). Late meningeal effects of myelographic contrast media with special reference to metrizamide. Br. J. Radiol. 51, 321-327.

Haughton, V.M., Ho, K.C. and Unger, G.F. (1977). Arachnoiditis following myelography with water-soluble agents. Radiology 125, 731-733.

Haughton, V.M., Eldevik, O.P., Ho, K.C., Larson, S.J. and Unger, G.F. (1978a). Arachnoiditis from experimental myelography with aqueous contrast media. Spine 3, 6569.

Haughton, V.M., Ho, K.C., Unger, G.F., Larson, S.J., Williams, A.L. and Eldevik, P. (1978b). Severity of postmyelographic arachnoiditis and concentration of meglumine iocarmate in primates. Am. J. Roentgenol. $130,313-316$. 
Haughton, V.M. and Ho, K.C. (1980). The risk of arachnoiditis from experimental nonionic contrast media. Radiology 136, 395-397.

Hoppenstein, R. (1980). A new approach to the failed, failed back syndrome, Spine 5, 371-379.

Howland, W.J., Curry, J.L. and Butler, A.K. (1963). Pantopaque arachnoiditis. Experimental study of blood as a potentiating agent. Radiology 80, 489-491.

Howland, W.J. and Curry, J.L. (1966). Experimental studies of Pantopaque arachnoiditis. I. Animal studies. Radiology 87, 253-257.

Hurteau, E.F., Baird, W.C. and Sinclair, E. (1954). Arachnoiditis following the use of iodised oil. J. Bone Joint Surg. 36, 393-396.

Iraci, G., Gerosa, L.T., Gerosa, M., Rigobello, L. and Zampieri, P. (1979). Opto-chiasmatic arachnoiditis in brothers. Ann. Ophthalmol. 11, 479-487.

Irstam, L. and Rosencrantz, M. (1973). Water-soluble contrast media and adhesive arachnoiditis. I. Reinvestigation of nonoperated cases. Acta Radiol. (Diagn) (Stockh) 14, 497-505.

Irstam, L. and Rosencrantz, M. (1974). Water-soluble contrast media and adhesive arachnoiditis. II. Reinvestigation of operated cases. Acta Radiol. (Diagn) (Stockh) 15, $1-15$.

Irstam, L., Sundstrom, R. and Sigstedt, B. (1974). Lumbar myelography and adhesive arachnoiditis. Acta. Radiol. (Diagn) (Stockh) 15, 356-368.

Irstam, L. (1978). Lumbar myelography with Amipaque. Spine 3, 70-82.

Jacobsen, H.H. and Lester, J. (1969). Diagnosis of spinal arachnoiditis by air myelography. Acta Neurol. Scand. 45, 376-379.

John, J.F. and Douglas, R.G. (1975). Tuberculous arachnoiditis. J. Pediatr. 86, 235-237.

Johnson, A.J. and Burrows, E.H. (1978). Thecal deformity after lumbar myelography with iophendylate (Myodil) and meglumine iothalamate (Conray 280). Br. J. Radiol. 51, 196-202.

Johnston, J.D.H. and Matheny, J.B. (1978). Microscopic lysis of lumbar adhesive arachnoiditis. Spine 3, 36-39.

Jorgensen, J., Hansen, P.H., Steenskov, V. and Ovesen, N. (1975). A clinical and radiological study of chronic lower spinal arachnoiditis, Neuroradiology 9, 139-144.

Kennedy, F., Effron, A.S. and Perry, G. (1950). The grave spinal cord paralyses caused by spinal anaesthesia. Surg. Gynecol. Obstet. 91, 385-398.

Krause, F. (1907). Zur Kenntnis der ruckenmarkslahmungen. Verh. Kongr. inn. Med. pt. 1, 109-113, pt. 2, 598-622.

Lazar, M.L. and Bland, J.E. (1979). Microsurgical intradural lysis and Silastic dural patch grafting in lumbar adhesive arachnoiditis (letter). Neurosurgery 5, 771-772.

Lear, M. and Harvey, S.C. (1924). The regeneration of the meninges. Ann. Surg. 80, 536-544.

Liliequist, B. and Lundstrom, B. (1974). Lumbar myelography and arachnoiditis. Neuroradiology 7, 9194.
Lombardi, G., Passerini, A. and Migliavacca, F. (1962). Spinal arachnoiditis. Br. J. Radiol. 35, 314-320.

Long, R.W. and Rachmaninoff, N. (1967). Spinal adhesive arachnoiditis with cyst formation: injection of cyst during myelography. J. Neurosurg. 27, 73-76.

McNeill, K.G., Harrison, J.E., Mirza, K.F., Tai-Pow, J., Geale, D.C. and Barnett, H.J.M. (1968). Thorium body burdens in humans following Thorotrast myelography and the incidence of myelopathy. Br. J. Radiol. 41, 755761.

McKenzie, T. (1971). Nocturnal enuresis as a late complication of meningitis. Br. Med. J. 4, 662-663.

Meyer, M.W., Powell, H.C., Wagner, M. and Niwayama, G. (1978). Thorotrast induced adhesive arachnoiditis associated with meningioma and schwannoma. Hum. Pathol. 9, 366-370.

Naiman, J.L., Rupprecht, L.M., Tanyeri, G. and Philippidis, P. (1970). Intrathecal methotrexate (letter). Lancet 1, 571.

Nelson, D.A. (1976). Arachnoiditis from intrathecally given corticosteroids in the treatment of multiple sclerosis (letter). Arch. Neurol. 33, 373.

Oliva, L.A. and Parenteau, A. L'arachnoidite spinale. Traitement de cinq cas. Union Med. Can. 94, 750-752.

Parker, K.R., Kane, J.T., Wicchers, D.O. and Johnson, E.W. (1979). Electromyographic changes reviewed in chronic spinal arachnoiditis. Arch. Phys. Med. Rehabil. 60, 320-322.

Peterson, H.O. (1976). Commentary on myelography: Defence of Pantopaque. In Current Controversies in Neurosurgery edited by Morley, T.P. Philadelphia, W.B. Saunders. 28-35.

Quiles, M., Marchisello, P.J. and Tsairis, P. (1978). Lumbar adhesive arachnoiditis. Etiologic and pathologic aspects. Spine 3, 45-50.

Radberg, C. and Wennberg, E. (1973). Late sequelae following lumbar myelography with water-soluble contrast media. Acta Radiol. (Diagn) (Stockh) 15, 1-15.

Ransford, A.O. and Harries, B.J. (1972). Localized arachnoiditis complicating lumbar disc lesions. J. Bone Joint Surg. 54B, 656-665.

Rao, S.B. and Dinakar, I. (1971). Cerebrospinal fluid protein in spinal compression. J. Indian M.A. 57, 165-166.

Reisner, L.S., Hochman, B.N. and Plumer, M.H. (1980). Persistent neurologic deficit and adhesive arachnoiditis following intrathecal 2-chloroprocaine injection. A nesth. Analg. 59, 452-454.

Savastano, A.A. (1968). Intrathecal steroid administration in postoperative arachnoiditis. R.I. Med. J. 51, 337-338.

Shaw, M.D.M., Russell, J.A. and Grossart, K.W. (1978). The changing pattern of spinal arachnoiditis. J. Neurol. Neurosurg. Psychiatry 41, 97-107.

Stookey, B. (1927). Adhesive spinal arachnoiditis simulating spinal cord tumour. Arch. Neurol. Psychiatr. 17, 158-178.

Smith, R.W. and Loeser, J.D. (1972). Myelographic variant in lumbar arachnoiditis. J. Neurosurg. 36, 441-446. 
Suolanen, J. (1977). Adhesive arachnoiditis after lumbar myelography. Ann. Clin. Res. 9, 257-260.

Teng, P. and Papatheodorou, C. (1967). Myelographic findings in adhesive spinal arachnoiditis. Brit. J. Radiol. 40, 201-208.

Tkaczuk, H. (1976). Intrathecal prednisolone therapy in postoperative arachnoiditis following operation of herniated disc. Acta Orthop. Scand. 47, 388-390.

Turnbull, I.M., Shulman, R. and Woodhurst, W.B. (1980). Thalamic stimulation for neuropathic pain. J. Neurosurg. 52, 486-493.

Wadia, N.H. and Dastur, D.K. (1969). Spinal meningitides with radiculo-myelopathy. I. Clinical and radiological features. J. Neurol. Sci. 8, 239-260.
Ward, W., Matheson, M. and Gonski, A. (1976). Three cases of granulomatous arachnoiditis after myelography. Med. J. Aust. 2, 333-335.

Wilber, M.C. (1975). Sedation of active acupuncture loci in the management of low back pain. Am. J. Chin. Med. 3, 275-279.

Wilkinson, H.A. and Schuman, N. (1979). Results of surgical lysis of lumbar adhesive arachnoiditis. Neurosurgery 4, 401-409.

Wolfgang, G.L. (1972). Neurotrophic arthropathy of the shoulder - a complication of progressive adhesive arachnoiditis. Clin. Orthop. 87, 217-221. 